the first recorded association of dysphagia with fluspirilene, although four episodes of dystonia and one dyskinetic reaction have occurred since 1975.

Acute dystonic reactions are well recognised with neuroleptic drugs,' but acute dystonic dysphagia has only recently been reported; NewtonJohn described the condition in two patients, the causal drug probably being metoclopramide, although prochlorperazine was implicated in one. ${ }^{2}$ The treatment of choice for acute dystonic reactions is an anticholinergic drug. Persistent dystonia, however, may prove resistant to drugs. The treatment options include anticholinergic drugs, levodopa, benzodiazepines, carbamazepine, tetrabenazine, and even phenothiazines or butyrophenones. ${ }^{3}$ Also, with the recognition of the therapeutic use of botulinum toxin $\mathrm{A}$ in spasmodic dysphonia $^{+}$this may offer an alternative acceptable solution to the problem of dystonic dysphagia when withdrawal of the causal neuroleptic is not clinically feasible.

1 Lader MH. Neuroleptics and abnormal movements. Br Med $\mathcal{F}$ 1982;285:463-4

2 Newton-John H. Acute upper airway obstruction due to supraglottic dystonia induced by a neuroleptic. Br Med $\mathcal{Y}$ 1988;297:964-5.

3 Anonymous. The management of dystonias. [Editorial.] Lancet $1985 ; \mathrm{i}: 321-2$

4 Marsden CD, Quinn NP. The dystonias. Br Med f 1990;300: $139-44$.

\section{Captopril and systemic lupus erythematosus syndrome}

Drs C Sieber, E Grimm, and F Follath (Division of Clinical Pharmacology, University Hospital, Basle, Switzerland) write: Lupoid skin reactions ${ }^{2}$ and haematological side effects ${ }^{3.5}$ induced by captopril have been recorded, but systemic lupus erythematosus syndrome induced by captopril is thought to be rare and of uncertain origin, and no conclusive case has been described.$^{67}$ We report on a patient taking captopril who developed signs of systemic lupus erythematosus syndrome.

A 53 year old man who had had insulin dependent diabetes mellitus since the age of 20 and had proved diabetic microangiopathy and macroangiopathy began treatment for hypertension and congestive heart failure with captopril $(25 \mathrm{mg}$ twice daily) in March 1987. He was already taking frusemide ( $40 \mathrm{mg}$ twice daily), isosorbide dinitrate (40 $\mathrm{mg}$ twice daily), and digoxin ( $0 \cdot 125 \mathrm{mg}$ daily). In September 1987 he presented with relapsing fever and bronchitis, which was treated with doxycycline ( $100 \mathrm{mg}$ daily) without any effect. In February 1988 his dose of captopril was increased to $125 \mathrm{mg}$ daily. Six weeks later the patient complained of arthralgias, fever, and malaise. At this time and subsequently all tests for rheumatoid factors gave negative results, including a test for antibodies to DNA. On admission to hospital in June 1988 the patient was in poor general health and showed, in addition to the symptoms described above, bilateral pleural effusions and a pericardial rub. There was also laboratory evidence for hepatopathy, with increased activity of transaminases.

After infections and other inflammatory agents that could have produced his symptoms had been excluded captopril was stopped. The concomitant drugs remained unchanged. He improved rapidly within five days, the pleural effusions regressed, and signs of pericarditis disappeared. His $\mathrm{Creactive}$ protein concentration, which was raised on ad mission at $7 \cdot 7 \mathrm{~g} / \mathrm{l}$ (normal $<0.5 \mathrm{~g} / \mathrm{l}$ ), fell to $2.7 \mathrm{~g} / \mathrm{l}$ one week later and to a normal value three months later. Simultaneously the increased activities of liver enzymes returned to normal. After he stopped captopril no signs of recurrence were observed.

In view of previous evidence of lupoid skin and haematological changes induced by captopril, the clinical history of this patient, who rapidly improved after stopping this angiotensin converting enzyme inhibitor, is suggestive of a drug induced systemic lupus erythematosus syndrome, although there were no antibodies to DNA-a common finding in drug induced lupus. ${ }^{8}$

Patri P, Nigro A, Rebora A. Lupus erythematosus-like eruption from captopril Acta Derm Venereol 1985;65:447-8.

2 Schmidt RE, Lange C. Lupus erythematodes durch captopril. Z Rheumatol 1982;41:182.

3 Brummelen P, Willemze R, Ran WD, et al. Captopril-associated agranulocytosis. Lancet 1980; i: 150 .

4 Elijovisch F, Krakoff LR. Captopril associated granulocytopenia in hypertension after renal transplantation. Lancet 1980;i:927.

5 Shindo K, Matsuya F, Ura T, et al. Captopril-associated granulocytopenia in hypertension after renal transplantation. Clin Nephrol 1984;22:314-6.

6 Kale SA. Drug-induced systemic lupus erythematosus: differentiating it from the real thing. Postgrad Med 1985;77: 231-42.

7 Hughes GRV. Recent developments in drug-associated systemic lupus erythematosus. Adverse Drug Reactions Bulletin 1987; 123:460-3.

8 Hughes GRV. Hypotensive agents, beta-blockers, and druginduced lupus. $\mathrm{Br} M e d$ f 1982;284:1358-9.

\section{Inhibitors of hydroxymethylglutaryl coenzyme A reductase for treating hypercholesterolaemia}

Drs Jacques D Barth, Olga A E Kruisbrink, and ANNELIES L VAN DiJK (Department of Cardiology, Radboud University Hospital Nijmegen, Nijmegen, The Netherlands) write The introduction of the hydroxymethylglutary coenzyme A reductase inhibitors heralded a new era in treating hypercholesterolaemia; they effectively lower lipid concentrations with few side effects. ${ }^{12}$ Their effect on the metabolism of the central nervous system, however, has been insufficiently investigated as the function of the central nervous system is lipid dependent. Schaefer indicated that lovastatin, but not pravastatin, may cross the blood-brain barrier and cause sleep disturbances, indicating that a lipophilic inhibito may be less desirable. ${ }^{3}$ Transient insomnia has been reported with lovastatin, ${ }^{145}$ and we therefore investigated the prevalence of these side effects with the related drug simvastatin in men with hypercholesterolaemia and symptoms of coronary artery disease.

Thirty men with coronary artery disease (who had had a myocardial infarction or coronary artery bypass grafting) were assessed by two dietitian primarily interested in dietary counselling. Patients were randomised in pairs to receive either simvastatin $(20 \mathrm{mg} /$ day) or colestipol ( $15 \mathrm{~g} /$ day). None of the patients had ever taken any other lipid lowering drugs. Duration and patterns of sleep were assessed by questionnaire. Patients were asked if they had ever experienced sleep problems, what time they went to bed to sleep, how they had slept the previous night, and when they had woken up.

None of the patients had previously complained of sleep problems. Patients taking simvastatin slept significantly less $(\mathrm{p}<0.01)$ than the matched controls taking colestipol (table). The main complaint of those who slept less was early awakening. Four of the patients taking simvastatin $(\mathbf{p}<0 \cdot 01)$ had repeated sleep interruptions. Neither the cardiological characteristics at baseline nor age (colestipol group: mean age 48, range 28-57; simvastatin group: $46,23-56$ ) were significantly different between the two groups.

Simvastatin seems to have undesirable side effects. Not only did insomnia persist for longer in patients taking this drug than in those taking

Mean (range) duration of sleep in men taking lipid lowering drugs

\begin{tabular}{|c|c|c|c|}
\hline $\begin{array}{l}\text { Duration of } \\
\text { treatment }\end{array}$ & $\begin{array}{c}\text { Simvastatin } \\
(\mathbf{n}=15)\end{array}$ & $\begin{array}{c}\text { Colestipol } \\
(n=15)\end{array}$ & $\mathrm{p}$ Value \\
\hline $\begin{array}{l}\text { Baseline } \\
3 \text { Months } \\
12 \text { Months }\end{array}$ & $\begin{array}{l}8 \mathrm{~h} 16 \mathrm{~min}(7 \mathrm{~h} 15 \mathrm{~min}-9 \mathrm{~h} 20 \mathrm{~min}) \\
7 \mathrm{~h} 12 \mathrm{~min}(6 \mathrm{~h} 15 \mathrm{~min}-8 \mathrm{~h} 40 \mathrm{~min}) \\
7 \mathrm{~h} 15 \mathrm{~min}(6 \mathrm{~h} 20 \mathrm{~min}-8 \mathrm{~h} 35 \mathrm{~min})\end{array}$ & $\begin{array}{l}8 \text { h } 7 \min (7 \text { h } 20 \min -9 \text { h } 15 \mathrm{~min}) \\
8 \text { h } 9 \min (7 \text { h } 15 \min -9 \text { h } 5 \text { min }) \\
8 \text { h } 3 \min (7 \text { h } 20 \min -9 \text { h } 10 \mathrm{~min})\end{array}$ & $\begin{array}{l}\text { NS } \\
<0.01 \\
<0.01\end{array}$ \\
\hline
\end{tabular}

colestipol but repeated sleep interruptions also occurred. The same reduction in cholesterol concentrations was obtained with both groups, suggesting that the reduction in cholesterol was not causing this effect. Although this was a small study and extrapolation should be done with care, simvastatin may have side effects related to its lipophilic character. Special attention should be directed to complaints of sleep disturbances.

I Hoeg JM, Brewer HB Jr. 3-Hydroxy-3-methylglutarylcenzyme A reductase inhibitors in the treatment of hypercholesterolemia. FAMA 1987;258:3532-6.

Lovastatin Study Group III. A multicenter comparison of ovastatin and cholestyramine therapy for severe primary hypercholesterolemia. FAMA 1988;260:359-66.

Schaefer EJ. HMG-CoA reductase inhibitors for hypercholesterolemia. N Engl f Med 1988;319:1222-3.

Sabra R. Topics in clinical pharmacology: lovastatin. $A m \mathcal{F}$ Med Sci 1988;296:426-8.

Dulces MN, Beeley L, eds. Side effects of drugs annual 12 . Amsterdam: Elsevier, 1988:379.

\section{Potentiation of action of warfarin by itraconazole}

Drs John Yeh, Shiu-Ching Soo, and ChrisTOPHER SUMmerton and Miss Christine RICHARDSON (Addenbrooke's Hospital, Cambridge CB2 2QQ) write: We report a case of enhanced action of warfarin associated with ora administration of itraconazole, a new triazole antifungal drug

A 61 year old woman was established on long term treatment with warfarin because of recurrent pulmonary embolism. The warfarin dose had been stable for the past 12 months at $5 \mathrm{mg}$ daily. She was also taking ipratropium bromide, salbutamol, and budesonide inhalers for asthma; quinine sulphate for nocturnal leg cramps; and omeprazole for intractable dyspepsia. All drugs had remained unchanged for over a year.

At a routine chest clinic review itraconazole $200 \mathrm{mg}$ twice daily was started for oral candidiasi induced by inhaled steroids. Four days later she presented to her general practitioner with generalised bruising and recurrent nose bleeds. An international normalised ratio greater than 8 was noted. Warfarin and itraconazole were stopped, but her other drugs remained unchanged. The following day she was admitted as a medical emergency with intractable bleeding and increased generalised bruising. Cardiovascular signs were stable and no other physical signs of disease were found. Her international normalised ratio remained greater than 8 . Her haemoglobin concentration was $107 \mathrm{~g} / \mathrm{l}$. White cell and platelet counts were normal. Values for plasma electrolytes and urea, liver function tests, and serum calcium and phosphate were all normal, as was her fibrinogen concentration.

She was treated with fresh frozen plasma. The bleeding stopped and did not recur. Her international normalised ratio returned to 2.4 over the course of two days, at which point warfarin was started. She was subsequently restabilised at her previous dose.

Itraconazole probably potentiated the effect of warfarin. Fluconazole, also a triazole antifungal drug, is known to enhance the effects of warfarin (Pfizer, personal communication). In premarketing studies itraconazole was not shown to affect the protein binding of warfarin (technical brochure on Sporanox, April 1989, Janssen). The mechanism of interaction between itraconazole and warfarin remains unclear. 